\title{
Pelvic floor disorders in postpartum adolescents in the Western Amazon: a cross-sectional study
}

This article was published in the following Dove Press journal:

International Journal of Women's Health

\author{
Lea Tami Suzuki Zuchelo1,2 \\ Edige Felipe de Sousa \\ Santos ${ }^{1,3}$ \\ Francisco Winter Dos \\ Santos Figueiredo ${ }^{1,4}$ \\ Fernando Adami ${ }^{4}$ \\ Italla Maria Pinheiro \\ Bezerra ${ }^{1,5}$ \\ Rodrigo Daminello \\ Raimundo' \\ Isabel Cristina Esposito \\ Sorpreso ${ }^{1,6}$ \\ Luiz Carlos de Abreu'
}

'Study Design and Scientific Writing Laboratory, ABC Medical School (FMABC), Santo André, SP, Brazil; ${ }^{2}$ School of Physiotherapy, Universidade Federal de Juiz de Fora (UFJF), Juiz de Fora, MG, Brazil; ${ }^{3}$ Department of Epidemiology, Universidade de São Paulo (USP), São Paulo, SP, Brazil; ${ }^{4}$ Epidemiology and Data Analysis Laboratory, ABC Medical School (FMABC), Santo André, SP, Brazil; ${ }^{5}$ Nursing Department, School of Sciences of Santa Casa de Misericórdia de Vitoria (EMESCAM), Vitória, ES, Brazil; ${ }^{6}$ Gynecology Discipline, Obstetrics and Gynecology Department, Faculdade de Medicina FMUSP, Universidade de São Paulo, São Paulo, SP, Brazil

Correspondence: Isabel Cristina Esposito Sorpreso Faculty of Medicine, University of São Paulo, Enéas de Carvalho Aguiar Avenue, n 255, $10^{\circ}$ Floor, Room 10166, Zipcode 05403-000, São Paulo, SP, Brazil Tel +55 I I 266। 762 I Email icesorpreso@usp.br
Purpose: To analyze the postpartum pelvic floor disorders (PFD) and mode of delivery among adolescents, late adolescents, and young women from Western Amazon.

Patients and methods: Cross-sectional study was carried out in the urban area of Western Amazon in the city of Rio Branco, Acre, Brazil, from October 2016 to February 2017. This is a convenience sample of women up to 30 years who completed six months postpartum, separated in three groups according to maternal age: adolescents (age $\leq 19$ years), late adolescents (20-24 years), and young women (25-30 years). Participants were home interviewed and answered Pelvic Floor Distress Inventory-20 (PFDI-20). Delivery clinical data were collected from patient's medical records.

Results: In total, 285 participants were interviewed: 41 adolescents, 103 late adolescents, and 141 young women. After controlling for confounding factors, prevalences of PFD were higher in the adolescents' group compared with the young women's group (urinary incontinence [UI], prevalence ratio $[\mathrm{PR}]=1.75,95 \% \mathrm{CI} 1.14-2.69$; urge urinary incontinence [UUI], $\mathrm{PR}=1.88,95 \%$ CI 1.02-3.47; stress urinary incontinence, $\mathrm{PR}=2.00,95 \% \mathrm{CI} 1.11-3.62$; fecal incontinence [FI], $\mathrm{PR}=4.40,95 \%$ CI 1.36-14.27). PFDI-20 scores also presented higher values in the adolescent group (Pelvic Organ Prolapse Distress Inventory [POPDI], PR =2.02, 95\% CI 1.49-2.75; urinary distress inventory [UDI], PR $=2.09,95 \%$ CI 1.47-2.98; PFDI, PR $=2.12,95 \%$ CI 1.47-2.98). Analyzing the influence of cesarean section, adolescents have higher prevalence of UI ( $\mathrm{PR}=1.84$, 95\% CI 1.04-3.26, $P=0.037)$, UUI ( $\mathrm{PR}=2.36,95 \% \mathrm{CI} 1.03-5.40, P=0.042)$, and FI $(\mathrm{PR}=4.09$, 95\% CI 1.21-13.81, $P=0.023$ ). In addition, POPDI ( $\mathrm{PR}=2.15,95 \% \mathrm{CI} 1.60-2.89, P<0.001)$, UDI $(\mathrm{PR}=2.25,95 \% \mathrm{CI} 1.61-3.16, P<0.001)$, and PFDI $(\mathrm{PR}=2.27,95 \% \mathrm{CI} 1.68-3.08, P<0.001)$ scores are also higher among adolescents where the baby is born by cesarean section.

Conclusion: Adolescents present higher prevalence and symptoms of PFD; furthermore, cesarean delivery has a greater negative influence on the pelvic floor of adolescents when compared with young women. This reinforces the importance of PFD investigation among the adolescent population, mainly in developing countries which have high rates of adolescent pregnancy and cesarean section.

Keywords: pelvic floor dysfunction, women's health, adolescent, puerperium

\section{Introduction}

Pelvic floor disorders (PFD) are widely related to childbirth in women in general. ${ }^{1-3}$ They include urinary incontinence (UI), fecal incontinence (FI), and pelvic organ prolapse (POP). The estimated prevalence of PFD is between $23 \%$ and $49 \%$ in the female population. ${ }^{4,5}$

Many studies have focused on the effect of childbirth on PFD, and advanced age is associated with more severe symptoms. ${ }^{6-8}$ There are fewer studies investigating PFD and the influence of mode of delivery in younger women, specifically in adolescents, 
and most of them analyze only urinary symptoms ${ }^{9-11}$ without comparison to older women.

Currently, there is no formal definition of adolescents, and the age range utilized varies by organization or agency. The World Health Organization (WHO) considers 10-19 years as the period of adolescence, which generally encompasses population statistics and is useful for health planning. ${ }^{12}$ The United Nations has defined "youth" as encompassing the age range 15-24 years. This is the period of transition from childhood to adulthood characterized by marked physical, emotional, and intellectual changes, which are important for the development of the individual and provide the foundation for functioning as an adult. ${ }^{13}$

Some studies have drawn attention to the lack of information from adolescents regarding pelvic floor health and PFD, including lack of understanding the risk factors for these pathologies. Adolescents' awareness and understanding of female anatomy, pelvic floor muscle, and PFD are scarce and may leave women unprepared for common life events including pregnancy and childbirth. ${ }^{14-16}$

According to data from the Brazilian Ministry of Health, the prevalence of childbirth in the adolescent population is $21.2 \%$, and the Western Amazon region presents percentages above the national average, with $28.1 \%$ of births in adolescent women. Moreover, between the period 1994 and 2015, this rate had not decreased, ${ }^{17}$ and therefore, the negative repercussions of pregnancy in adolescence arise as a public health problem, and pelvic floor dysfunction must be investigated because of the impact on quality of life. ${ }^{18}$

The influence of mode of delivery on the occurrence of PFD in adolescents is unknown. In women in general, vaginal delivery has been considered the main contributing factor for the development of PFD; however cesarean delivery is not shown as the best choice for the prevention of these symptoms in addition to the health risks for both fetus and mother. ${ }^{19,20}$

Therefore, this study aims to analyze the postpartum PFD and mode of delivery among adolescents, late adolescents, and young women from Western Amazon.

\section{Patients and methods Study design}

Cross-sectional study was carried out in the urban area of Western Amazon in the city of Rio Branco, Acre, Brazil, from October 2016 to February 2017, according to STROBE recommendations. ${ }^{21}$

\section{Sample study}

This is a convenience sample of 285 women selected from the newborns' register book of the reference hospitals: Maternidade
Bárbara Heliodora and Hospital Santa Juliana. The minor sample size result was 142 women and was calculated by infinite population equation in non-proballistic sample based on prevalence of $10.3 \%$ of PFD in women aged 19-30 years enrolled at the University of Alabama at Birmingham. ${ }^{14}$ A confidence level of $95 \%$ and sampling error of 5\% was considered.

Women up to 30 years of age who completed six months postpartum were included. The period of six months was chosen because this is the physiological time of restoration of muscle tone and connective tissue to the prepregnant state. ${ }^{22}$ Exclusion criteria were stillbirth, preterm birth below 24 weeks, women who underwent previous urogenital surgeries, and women with cognitive impairment making it difficult to complete the questionnaires.

Participants were separated into three groups according to international standards of the World Health Organization and The United Nation's classification of maternal age: 1) adolescents' group: with women up to 19 years of age; ${ }^{12}$ 2) late adolescents' group: with women aged 20-24 years; 3 ) young women's group with women aged 25-30 years. ${ }^{13}$

\section{Data collection}

A telephone contact was made to invite volunteer participation in the research, to schedule a home interview, and to sign an informed consent form. All participants signed the written informed consent, and parents or legal guardians of participants under 18 years old also signed written informed consent. The research project and participant's informed consent terms were approved by UniNorte Ethics Committee of the Barão do Rio Branco Faculty (protocol n 1.736.839).

All women were asked to answer the questionnaires themselves and if they had any questions, a trained member of the research group would assist in filling out the questionnaires.

The sociodemographic questionnaires included maternal age, smoking habits, marital status, body mass index, physical activity practice, contraceptive method, breastfeeding, parity, and years of study.

The questionnaire also included a Portuguese translation of the Pelvic Floor Distress Inventory (PFDI-20). ${ }^{23,24}$ It included 20 questions divided into three scales (Urinary Distress Inventory-6 [UDI-6], Pelvic Organ Prolapse Distress Inventory-6 [POPDI-6], and Colorectal-Anal Distress Inventory-8 [CRADI-8]), each with a score of 0 to 100 and the final score was obtained by the sum of the three scales. The higher the score on the PFDI-20 scale, the greater the symptoms of PFD.

The presence of UI was categorized by participants who answered YES to any of the following questions: "16-Do you 
usually experience urine leakage associated with a feeling of urgency, that is, a strong sensation of needing to go to the bathroom?"; "17-Do you usually experience urine leakage related to coughing, sneezing, or laughing?"; "18-Do you usually experience small amounts of urine leakage (that is, drops)?"

The presence of urge urinary incontinence (UUI) was categorized by participants who answered YES to the following question: "16-Do you usually experience urine leakage associated with a feeling of urgency, that is, a strong sensation of needing to go to the bathroom?"

The presence of stress urinary incontinence (SUI) was categorized by participants who answered YES to the following question: "17-Do you usually experience urine leakage related to coughing, sneezing, or laughing?"

The presence of FI was categorized by participants who answered YES to any of the following questions: "9-Do you usually lose stool beyond your control if your stool is well formed?" or "10-Do you usually lose stool beyond your control if your stool is loose?"

The presence of POP was categorized by participants who answered YES to the following question: "3-Do you usually have a bulge or something falling out that you can see or feel in your vaginal area?"

Delivery clinical data were collected from patients' medical records after agreement of participation (number of prenatal visits; mode of delivery - vaginal, instrumental, and cesarean; newborn's clinical and anthropometric outcomes; episiotomy; and spontaneous perineal tears).

The terminology used in this article follows the International Urogynecological Association (IUGA)/International Continence Society (ICS) joint report on terminology for female pelvic floor dysfunction. ${ }^{25}$

\section{Statistical analysis}

Statistical analysis was performed by the Statistics Data Analysis for Windows (Stata ${ }^{\circledR}$, StataCorp, LLC, 13.0, College Station, TX, USA). Qualitative variables are presented by absolute and relative frequencies, and quantitative variables are presented by the median value and CI, as they did not show adherence to the normal distribution (evaluated by the Kolmogorov-Smirnov test). The analysis of the association between groups and qualitative variables was performed using the chi-squared test, and for quantitative variables, the Kruskal-Wallis test.

For statistical analysis, the results of PFDI-20 scores and subscores were dichotomized by the median. From the value of zero to the median (including median) it indicated the absence of symptoms. However, from scores greater than the median it indicated the presence of symptoms. ${ }^{26}$
To compare the prevalence of PFD symptoms (UI, FI, and POP) and PFDI-20 scores among adolescents, late adolescents, and young women (reference group), the Poisson regression model with robust variance was used. The prevalence ratio (PR) with 95\% CI from the adjusted model was corrected based on clinical knowledge from previous studies ${ }^{6,27,28,32}$ and sociodemographic variables with statistical difference in group homogeneity analysis. Therefore, we selected the following confounding factors: body mass index (BMI), parity, employment, mode of delivery, and newborn head circumference perimeter.

The information not supplied by the participants or absent from the hospital records was considered missing. All analyses were bi-caudal, and $P<0.05$ was considered as statistically significant.

\section{Results}

In total, 285 participants from the Western Amazon were interviewed. Almost $60 \%$ of all participants had a partner, $48 \%$ were employed, $5 \%$ smoked, $75 \%$ used contraceptive methods, $60.4 \%$ breastfed until six months; over $80 \%$ were sedentary, and $37 \%$ had studied for more than 12 years.

The adolescents group included 41 women with ages varying from 16 to 19 years, and the median age in this group was 18 years, 95\% CI 18-19; the late adolescents group included 103 women and the median age was 22 years, 95\% CI 21-22; the young women's group included 141 women and the median age was 27 years, 95\% CI 27-28. A comparison of sociodemographic characteristics between groups is shown in Table 1 .

Comparing the three groups, late adolescents group were less likely to be employed $(P=0.011)$. Other sociodemographic characteristics were similar between groups.

A comparison of maternal clinical characteristics and delivery data between groups was performed in Table 2 . Maternal BMI and parity were significantly greater in the young women's group ( $P=0.007$ and $P<0.001$, respectively). In relation to the mode of delivery, the adolescents' group had more vaginal and instrumental delivery when compared with the other groups (late adolescents' group and young women's group, $P=0.002$ ).

There were no differences between groups related to maternal weight gain and weight loss (during pregnancy and postpartum, respectively), prenatal care, perineal tears, episiotomy, gestational age at birth, and newborn's clinical and anthropometrics outcomes.

In the total population, the prevalence of the main outcomes was as follows: UI 34.4\% (98/285), UUI $21.1 \%$ (60/285), SUI 20.7\% (59/285), FI 7.0\% (20/285), and POP symptoms $4.9 \%(14 / 285)$. 
Table I Sociodemographic data according to maternal age, Brazilian Western Amazon, 2016-20I7

\begin{tabular}{|c|c|c|c|c|c|}
\hline \multirow[t]{2}{*}{ Variables } & \multirow[t]{2}{*}{ Categories } & \multirow{2}{*}{$\begin{array}{l}\text { Adolescents } \\
(\leq 19 \text { years) } \\
\text { Total } n=41 \\
n(\%)\end{array}$} & \multirow{2}{*}{$\begin{array}{l}\text { Late adolescents } \\
\text { (20-24 years) } \\
\text { Total } n=103 \\
n(\%)\end{array}$} & \multirow{2}{*}{$\begin{array}{l}\text { Young women } \\
\text { (25-30 years) } \\
\text { Total } n=14 \mid \\
n(\%)\end{array}$} & \multirow[t]{2}{*}{ P-value* } \\
\hline & & & & & \\
\hline \multirow[t]{2}{*}{ Have a partner } & Yes & $21(51.2)$ & $56(54.9)$ & $91(65)$ & 0.149 \\
\hline & No & $20(48.8)$ & $46(45.1)$ & $49(35)$ & \\
\hline \multirow[t]{2}{*}{ Employed } & Yes & $21(5 \mid .2)$ & $36(36.0)$ & $78(55.3)$ & 0.011 \\
\hline & No & $20(48.8)$ & $64(64.0)$ & $63(44.7)$ & \\
\hline \multirow[t]{2}{*}{ Smoking } & Yes & $4(9.8)$ & $7(6.8)$ & $3(2.1)$ & 0.075 \\
\hline & No & $37(90.2)$ & $96(93.2)$ & I 38 (97.9) & \\
\hline Contraceptive & Yes & $74(75.5)$ & $28(71.8)$ & $102(75.6)$ & 0.883 \\
\hline method & No & $24(24.5)$ & II (28.2) & $33(24.4)$ & \\
\hline \multirow[t]{2}{*}{ Breastfeeding } & Yes & $27(65.8)$ & $55(53.4)$ & $89(64.0)$ & 0.184 \\
\hline & No & $14(34.2)$ & $48(46.6)$ & $50(36.0)$ & \\
\hline \multirow[t]{2}{*}{ Physical activity } & Yes & $13(3 \mid .7)$ & $19(18.4)$ & $24(17.0)$ & 0.106 \\
\hline & No & $28(68.3)$ & $84(81.6)$ & $117(83.0)$ & \\
\hline \multirow[t]{3}{*}{ Scholarity } & Less than 8 years & $4(9.8)$ & $12(11.8)$ & $10(7.1)$ & 0.528 \\
\hline & $8-12$ years & $19(46.3)$ & 57 (55.9) & $75(53.6)$ & \\
\hline & More than 12 years & 18 (43.9) & $33(32.3)$ & $55(39.3)$ & \\
\hline
\end{tabular}

Note: *Chi-squared test.

Table 2 Maternal clinical characteristics and delivery outcomes according to maternal age, Brazilian Western Amazon, 2016-20I7

\begin{tabular}{|c|c|c|c|c|c|}
\hline \multirow[t]{2}{*}{ Variables } & \multirow[t]{2}{*}{ Categories } & $\begin{array}{l}\text { Adolescents } \\
\text { ( } \leq 19 \text { years) } \\
\text { Total } n=41 \\
\end{array}$ & $\begin{array}{l}\text { Late adolescents } \\
(20-24 \text { years) } \\
\text { Total } n=103 \\
\end{array}$ & $\begin{array}{l}\text { Young women } \\
\text { (25-30 years) } \\
\text { Total } n=|4| \\
\end{array}$ & \multirow[t]{2}{*}{$P$-value* } \\
\hline & & n (\%) & n (\%) & n (\%) & \\
\hline \multirow[t]{3}{*}{ Parity } & One births & $29(70.7)$ & $65(63.1)$ & $56(39.7)$ & $<0.001$ \\
\hline & Two births & II (26.8) & $29(28.2)$ & $57(40.4)$ & \\
\hline & $\geq 3$ births & I (2.5) & $9(8.7)$ & $28(19.9)$ & \\
\hline \multirow[t]{2}{*}{ Prenatal visits } & $<6$ visits & $30(33.7)$ & $13(35.1)$ & $28(21.7)$ & 0.085 \\
\hline & $\geq 6$ visits & $59(66.3)$ & $24(64.9)$ & I0I (78.3) & \\
\hline \multirow[t]{3}{*}{ Mode of delivery } & Vaginal & $21(5 \mid .2)$ & $44(42.7)$ & $49(34.7)$ & 0.002 \\
\hline & Cesarean & $18(43.9)$ & $59(57.3)$ & $92(65.3)$ & \\
\hline & Vacuum & $2(4.9)$ & 0 & 0 & \\
\hline \multirow[t]{2}{*}{ Perineal tears } & Yes & $8(19.5)$ & $12(11.6)$ & $13(9.4)$ & 0.211 \\
\hline & No & $33(80.5)$ & 91 (88.4) & $125(90.6)$ & \\
\hline \multirow[t]{2}{*}{ Episiotomy } & Yes & I (2.4) & I (I.0) & $2(1.4)$ & 0.796 \\
\hline & No & $40(97.6)$ & $102(99.0)$ & $139(98.6)$ & \\
\hline \multirow[t]{3}{*}{ Gestational age } & Preterm & $4(10.5)$ & $13(14.1)$ & 15 (II.4) & 0.918 \\
\hline & Term & $34(89.5)$ & $78(84.8)$ & $116(88.9)$ & \\
\hline & Post-term & 0 & $\mathrm{I}(\mathrm{I} . \mathrm{I})$ & I (0.7) & \\
\hline Newborn respiratory & Yes & $4(10.5)$ & $6(6.5)$ & $16(12.4)$ & 0.343 \\
\hline \multirow[t]{2}{*}{ dysfunction } & No & $34(89.5)$ & $87(93.5)$ & $113(87.6)$ & \\
\hline & & Median $(95 \% \mathrm{Cl})$ & Median $(95 \% \mathrm{Cl})$ & Median $(95 \% \mathrm{Cl})$ & $P$-value** \\
\hline BMI & & 22.49 (20.99 to 24.8$)$ & 24.46 (22.66 to 25.68$)$ & 24.88 (23.94 to 26.03$)$ & 0.007 \\
\hline Weight gain & & II (8.0 to I4.3) & II (9.7 to I3) & $12(10$ to 13$)$ & 0.925 \\
\hline Weight loss & & $-10(-12.3$ to 9.0$)$ & $-9(-10.1$ to -8.0$)$ & $-10(-11$ to -8.26$)$ & 0.790 \\
\hline Birth weight & & $3,420(3,207$ to $3,483.97)$ & $3,275(3,140$ to 3,379$)$ & $3,3 \mid 7.5(3,210$ to $3,395.4)$ & 0.324 \\
\hline Birth stature & & 49 (48 to 49.3$)$ & 49 (48 to 49$)$ & 49 (48 to 49$)$ & 0.647 \\
\hline Newborn HC & & 34 (34 to 35$)$ & 34 (34 to 35$)$ & 35 (34 to 35$)$ & 0.636 \\
\hline Newborn CC & & 34 (33 to 35$)$ & 34 (33 to 34$)$ & 34 (33 to 34$)$ & 0.701 \\
\hline Newborn Apgar I' & & 8.5 (8 to 9$)$ & 8 (8 to 9$)$ & 8 (8 to 9$)$ & 0.940 \\
\hline
\end{tabular}

Notes: *Chi-squared test; **Kruskal-Wallis test.

Abbreviations: BMI, body mass index; newborn HC, newborn head circumference; newborn CC, newborn chest circumference. 
The results of the PFDI-20 scores and UI, UUI, SUI, FI, and POP prevalences the young women's group were compared with the groups of adolescents and late adolescents and are presented in Table 3.

The prevalences of UI, UUI, SUI, and FI were higher the adolescents' group compared with the young women's group. By the Poisson regression model in the adjusted analysis, the prevalences of UI ( $\mathrm{PR}=1.75,95 \% \mathrm{CI} 1.14-2.69$, $P=0.010)$, UUI ( $\mathrm{PR}=1.88,95 \% \mathrm{CI} 1.02-3.47, P=0.043)$, SUI $(\mathrm{PR}=2.00,95 \% \mathrm{CI} 1.11-3.62, P=0.021)$, and $\mathrm{FI}(\mathrm{PR}=4.40$,
$95 \%$ CI 1.36-14.27, $P=0.014$ ) were statistically higher in the adolescents' group compared with the young women's group. In the crude analysis, only the prevalences of UI and FI were statistically higher comparing the same groups.

About the PFDI-20 scores, comparing young women's group and adolescents' group, the following scores presented higher values in the adolescents' group, by the Poisson regression model in the adjusted analysis: POPDI scores (PR = $2.02,95 \%$ CI 1.49-2.75, $P<0.001)$, UDI score ( $P R=2.09$, $95 \%$ CI 1.47-2.98, $P<0.001)$, and PFDI score ( $P R=2.12$,

Table 3 PFDI-20 questionnaire outcomes comparing adolescents, late adolescents, and young women, Brazilian Western Amazon, 2016-2017

\begin{tabular}{|c|c|c|c|c|c|c|}
\hline & \multicolumn{2}{|c|}{ Symptoms } & \multicolumn{2}{|l|}{ Crude model* } & \multicolumn{2}{|l|}{ Adjusted model* } \\
\hline & No & Yes & PR (95\% Cl) & $P$-value & PR (95\% CI) & $P$-value \\
\hline & n (\%) & n (\%) & & & & \\
\hline \multicolumn{7}{|l|}{ POPDI score } \\
\hline Young women & $84(59.6)$ & $57(40.4)$ & Reference & & Reference & \\
\hline Late adolescents & $52(50.5)$ & 51 (49.5) & $1.22(0.93-1.62)$ & 0.156 & $1.40(1.05-1.86)$ & 0.022 \\
\hline Adolescents & $12(29.3)$ & $29(70.7)$ & $1.75(1.32-2.32)$ & $<0.001$ & $2.02(1.49-2.75)$ & $<0.001$ \\
\hline \multicolumn{7}{|l|}{ CRADI score } \\
\hline Young women & 91 (64.5) & $50(35.5)$ & Reference & & Reference & \\
\hline Late adolescents & $56(54.4)$ & $47(45.6)$ & $1.29(0.95-1.75)$ & 0.108 & I.23 (0.89-I.7I) & 0.211 \\
\hline Adolescents & $20(48.8)$ & $2 \mid(5 \mid .2)$ & $1.44(0.99-2.10)$ & 0.054 & $1.42(0.96-2.10)$ & 0.076 \\
\hline \multicolumn{7}{|l|}{ UDI score } \\
\hline Young women & $91(64.5)$ & $50(35.5)$ & Reference & & Reference & \\
\hline Late adolescents & $61(59.2)$ & $42(40.8)$ & I.I5 (0.83-1.59) & 0.396 & $1.25(0.90-1.76)$ & 0.186 \\
\hline Adolescents & $15(36.6)$ & $26(63.4)$ & $1.79(1.30-2.47)$ & $<0.001$ & $2.09(1.47-2.98)$ & $<0.001$ \\
\hline \multicolumn{7}{|l|}{ PFDI total score } \\
\hline Young women & $84(59.6)$ & $57(40.4)$ & Reference & & Reference & \\
\hline Late adolescents & $50(48.5)$ & $53(51.5)$ & $1.27(0.97-1.68)$ & 0.085 & $1.35(1.01-1.8 \mathrm{I})$ & 0.040 \\
\hline Adolescents & $10(24.4)$ & $31(75.6)$ & $1.87(1.43-2.44)$ & $<0.001$ & $2.12(1.57-2.87)$ & $<0.001$ \\
\hline \multicolumn{7}{|l|}{ UI } \\
\hline Young women & $100(70.9)$ & $41(29.1)$ & Reference & & Reference & \\
\hline Late adolescents & $66(64.1)$ & 37 (35.9) & $1.24(0.86-1.78)$ & 0.257 & $1.27(0.86-1.88)$ & 0.228 \\
\hline Adolescents & $21(5 I .2)$ & $20(48.8)$ & $1.68(1.12-2.52)$ & 0.013 & $1.75(1.14-2.69)$ & 0.010 \\
\hline \multicolumn{7}{|l|}{ UUI } \\
\hline Young women & II 4 (80.9) & $27(19.1)$ & Reference & & Reference & \\
\hline Late adolescents & $83(80.6)$ & $20(19.4)$ & I.0I (0.60-I.7I) & 0.958 & $\mathrm{I} .04(0.59-\mathrm{I} .8 \mathrm{I})$ & 0.898 \\
\hline Adolescents & $28(68.3)$ & $13(31.7)$ & $1.66(0.94-2.91)$ & 0.080 & $1.88(1.02-3.47)$ & 0.043 \\
\hline \multicolumn{7}{|l|}{ SUI } \\
\hline Young women & II4 (80.9) & $27(19.1)$ & Reference & & Reference & \\
\hline Late adolescents & $84(81.6)$ & $19(18.4)$ & $0.96(0.57-1.64)$ & 0.890 & $1.09(0.63-1.91)$ & 0.750 \\
\hline Adolescents & $28(68.3)$ & I 3 (3|.7) & $1.66(0.94-2.91)$ & 0.080 & $2.00(1.11-3.62)$ & 0.021 \\
\hline \multicolumn{7}{|l|}{$\mathrm{FI}$} \\
\hline Young women & $135(95.7)$ & $6(4.26)$ & Reference & & Reference & \\
\hline Late adolescents & $97(94.2)$ & $6(5.8)$ & $1.37(0.45-4.13)$ & 0.577 & I. $46(0.40-5.27)$ & 0.567 \\
\hline Adolescents & $33(80.5)$ & $8(19.5)$ & $4.59(1.68-12.48)$ & 0.003 & $4.40(1.36-14.27)$ & 0.014 \\
\hline \multicolumn{7}{|l|}{ POP } \\
\hline Young women & I35 (95.7) & $6(4.3)$ & Reference & & Reference & \\
\hline Late adolescents & $97(94.2)$ & $6(5.8)$ & $1.37(0.45-4.13)$ & 0.577 & $1.52(0.50-4.63)$ & 0.457 \\
\hline Adolescents & $39(95.1)$ & $2(4.9)$ & $1.14(0.24-5.48)$ & 0.864 & $1.95(0.34-11.04)$ & 0.450 \\
\hline
\end{tabular}

Note: *Poisson Regression model with robust variance.

Abbreviations: PFDI-20, Pelvic Floor Distress Inventory-20; PR, prevalence ratio; POPDI, Pelvic Organ Prolapse Distress Inventory; CRADI, Colorectal Anal Distress Inventory; UDI, Urinary Distress Inventory; PFDI, Pelvic Floor Distress Inventory; UI, urinary incontinence; UUI, urge urinary incontinence; SUI, stress urinary incontinence; $\mathrm{Fl}$, fecal incontinence; POP, pelvic organ prolapse. 
95\% CI 1.47-2.98, $P<0.001)$, with statistically significant difference, which represents an increase in the reported symptoms in adolescents' group.

In comparing late adolescents' group with young women's group, the POPDI score (PR $=1.40,95 \%$ CI $1.05-1.86$, $P=0.022)$ and PFDI score $(\mathrm{PR}=1.35,95 \%$ CI $1.01-1.81$, $P=0.040$ ) presented statistically higher values in the late, adolescents' group only in adjusted analysis, which represents an increase in the reported symptoms.

Analyzing the influence of cesarean delivery in the prevalence of PFD symptoms among the age groups (Table 4), we identified that the adolescents' group have higher prevalence of UI $(\mathrm{PR}=1.84,95 \%$ CI 1.04-3.26, $P=0.037)$, UUI ( $P R=2.36,95 \%$ CI $1.03-5.40, P=0.042)$, and FI $(\mathrm{PR}=4.09$, 95\% CI 1.21-13.81, $P=0.023)$ when compared with the young women's group. In addition, the POPDI (PR $=2.15,95 \%$ CI 1.60-2.89, $P<0.001)$, UDI $(\mathrm{PR}=$ $2.25,95 \%$ CI 1.61-3.16, $P<0.001)$, and PFDI $(\mathrm{PR}=2.27$, $95 \%$ CI $1.68-3.08, P<0.001)$ scores were also statistically higher in adolescents' group.

Comparing the late adolescents' group and young women's group, only the POPDI score (PR $=1.40,95 \%$ CI 1.00-1.94, $P=0.047$ ) was statistically higher in the late adolescents' group.

Table 4 PFDI-20 questionnaire outcomes comparing adolescents, late adolescents, and young women, according to mode of delivery, Brazilian Western Amazon, 2016-2017

\begin{tabular}{|c|c|c|c|c|c|c|c|c|}
\hline & \multicolumn{4}{|c|}{ Vaginal delivery } & \multicolumn{4}{|c|}{ Cesarean delivery } \\
\hline & No N (\%) & Yes N (\%) & PR (95\% Cl)* & $P$-value* & No N (\%) & Yes N (\%) & PR (95\% CI)* & $P$-value* \\
\hline \multicolumn{9}{|l|}{ POPDI score } \\
\hline Young women & $30(6 I .2)$ & $19(38.8)$ & Reference & & $54(58.7)$ & $38(4 \mid .3)$ & Reference & \\
\hline Late adolescents & $27(61.4)$ & $17(38.6)$ & $1.00(0.60-1.67)$ & 0.989 & $25(42.4)$ & $34(57.6)$ & $1.40(1.00-1.94)$ & 0.047 \\
\hline Adolescents & 9 (42.9) & $12(57.1)$ & I.47 (0.88-2.46) & 0.139 & $2(I I . I)$ & 16 (88.9) & $2.15(1.60-2.89)$ & $<0.001$ \\
\hline \multicolumn{9}{|l|}{ CRADI score } \\
\hline Young women & $32(65.3)$ & $17(34.7)$ & Reference & & $59(64.1)$ & 33 (35.9) & Reference & \\
\hline Late adolescents & $26(59.1)$ & 18 (40.9) & I.18 (0.70-1.99) & 0.539 & $30(50.9)$ & $29(49.1)$ & $1.37(0.94-2.00)$ & 0.102 \\
\hline Adolescents & $12(57.1)$ & $9(42.9)$ & $1.24(0.66-2.32)$ & 0.510 & $8(44.4)$ & $10(55.6)$ & $1.55(0.94-2.55)$ & 0.084 \\
\hline \multicolumn{9}{|l|}{ UDI score } \\
\hline Young women & $33(67.4)$ & $16(32.6)$ & Reference & & $58(63.0)$ & $34(37.0)$ & Reference & \\
\hline Late adolescents & $30(68.2)$ & $14(31.8)$ & $0.97(0.54-1.76)$ & 0.932 & $31(52.5)$ & $28(47.5)$ & $1.28(0.88-1.88)$ & 0.197 \\
\hline Adolescents & $10(47.6)$ & II (52.4) & $1.60(0.90-2.85)$ & 0.107 & $3(16.7)$ & $15(83.3)$ & $2.25(1.61-3.16)$ & $<0.001$ \\
\hline \multicolumn{9}{|l|}{ PFDI total score } \\
\hline Young women & $28(57.1)$ & $21(42.9)$ & Reference & & $56(60.9)$ & $36(39.1)$ & Reference & \\
\hline Late adolescents & $23(52.3)$ & $21(47.7)$ & I.II (0.7I-I.75) & 0.639 & $27(45.8)$ & $32(54.2)$ & $1.39(0.98-1.96)$ & 0.065 \\
\hline Adolescents & $8(38.1)$ & $13(6 \mid .9)$ & $1.44(0.90-2.30)$ & 0.124 & $2(11.1)$ & $16(88.9)$ & $2.27(1.68-3.08)$ & $<0.001$ \\
\hline \multicolumn{9}{|l|}{ UI } \\
\hline Young women & $33(67.4)$ & $16(32.6)$ & Reference & & 67 (72.8) & 25 (27.2) & Reference & \\
\hline Late adolescents & $27(61.4)$ & $17(38.6)$ & I.I8 (0.68-2.05) & 0.549 & $39(66.1)$ & $20(33.9)$ & $1.25(0.76-2.04)$ & 0.377 \\
\hline Adolescents & $10(47.6)$ & II (52.4) & $1.60(0.90-2.85)$ & 0.107 & $9(50.0)$ & $9(50.0)$ & $1.84(1.04-3.26)$ & 0.037 \\
\hline \multicolumn{9}{|l|}{ UUI } \\
\hline Young women & 35 (7I.4) & $14(28.6)$ & Reference & & 79 (85.9) & $13(14.1)$ & Reference & \\
\hline Late adolescents & $36(81.8)$ & $8(18.2)$ & $0.64(0.29-1.38)$ & 0.250 & 47 (79.7) & $12(20.3)$ & $1.44(0.70-2.94)$ & 0.318 \\
\hline Adolescents & $14(66.7)$ & $7(33.3)$ & $1.17(0.55-2.48)$ & 0.688 & $12(66.7)$ & $6(33.3)$ & $2.36(1.03-5.40)$ & 0.042 \\
\hline \multicolumn{9}{|l|}{ SUI } \\
\hline Young women & $40(81.6)$ & $9(18.4)$ & Reference & & $74(80.4)$ & $18(19.6)$ & Reference & \\
\hline Late adolescents & $37(84.1)$ & $7(I 5.9)$ & $0.87(0.35-2.14)$ & 0.755 & 47 (79.7) & $12(20.3)$ & $1.04(0.54-2.00)$ & 0.908 \\
\hline Adolescents & I5 (7I.4) & $6(28.6)$ & $1.56(0.63-3.83)$ & 0.337 & II (6I.I) & 7 (38.9) & $1.99(0.97-4.06)$ & 0.059 \\
\hline \multicolumn{9}{|l|}{$\mathrm{FI}$} \\
\hline Young women & $48(98.0)$ & I (2.0) & Reference & & $87(94.6)$ & $5(5.4)$ & Reference & \\
\hline Late adolescents & $44(100)$ & 0 & NA & NA & $53(89.8)$ & $6(10.2)$ & $1.87(0.60-5.88)$ & 0.283 \\
\hline Adolescents & 17 (80.9) & $4(19.1)$ & $9.33(1.10-79.32)$ & 0.041 & 14 (77.8) & $4(22.2)$ & $4.09(1.2|-| 3.8 \mid)$ & 0.023 \\
\hline \multicolumn{9}{|l|}{ POP } \\
\hline Young women & $46(93.9)$ & $3(6.1)$ & Reference & & 89 (96.7) & $3(3.3)$ & Reference & \\
\hline Late adolescents & $4 \mid(93.2)$ & $3(6.8)$ & I.II (0.24-5.27) & 0.892 & $56(94.9)$ & $3(5.1)$ & $1.56(0.32-7.50)$ & 0.579 \\
\hline Adolescents & $20(95.2)$ & I (4.8) & $0.78(0.08-7.12)$ & 0.824 & $17(94.4)$ & I (5.6) & $1.70(0.19-15.57)$ & 0.637 \\
\hline
\end{tabular}

Note: *Poisson Regression model with robust variance.

Abbreviations: PFDI-20, Pelvic Floor Distress Inventory-20; PR, prevalence ratio; POPDI, Pelvic Organ Prolapse Distress Inventory; CRADI, Colorectal Anal Distress Inventory; NA, not applicable, as no case was detected for this category; UDI, Urinary Distress Inventory; PFDI, Pelvic Floor Distress Inventory; UI, urinary incontinence; UUl, urge urinary incontinence; SUI, stress urinary incontinence; FI, fecal incontinence; POP, pelvic organ prolapse. 
In relation to the influence of vaginal delivery in the prevalence of PFD symptoms among the age groups (Table 4), we identified that only the prevalence of FI (PR $=9.33,95 \%$ CI $1.10-79.32, P=0.041)$ was statistically higher in adolescents' group when compared with the young women's group. There were no cases of FI in the late adolescents' group.

\section{Discussion}

In this cross-sectional study carried out in Western Amazon, the prevalence of PFD symptoms was assessed six months after delivery by PFDI-20 questionnaire. The results show that adolescents' group presents higher prevalence of PFD and higher scores in the PFDI-20 questionnaire, which characterizes higher reports of PFD symptoms when compared with young women's group. Moreover, cesarean delivery has a greater negative influence on adolescents' group when compared with the young women's group.

According to previous studies, advanced age and vaginal delivery were identified as risk factors for PFD, ${ }^{29-31}$ but the prevalence of these symptoms among adolescents and young adults in the postpartum period is rarely investigated. Increased BMI is also described as a risk factor, ${ }^{32}$ but in our study, though adolescents presented lower BMI and parity, they were the population with the highest prevalence of PFD symptoms, which leads us to think about these symptoms in adolescents.

Preterm birth is a common complication among adolescents, ${ }^{33,34}$ but in our study, preterm birth was proportionally lower among adolescents, although it did not have a statistically significant difference. Perhaps other socioeconomic aspects (marital status, prenatal visits, scholarity, and smoking habits) have a greater influence on prematurity, and our study population was homogeneous among age groups regarding these factors.

In relation to UI, the prevalence found in adolescents' group was $48.8 \%$ and for UUI and SUI was $31.7 \%$. These values are above the reference population, with prevalence of UI $29.1 \%$ for the young women's group and for UUI and SUI $28.6 \%$ and $18.1 \%$, respectively. Comparing these results with previous studies, we identified that prevalences of UI found in the adolescents' group are also above that found in the general population, which are around $23 \%-38 \%$ for UI in general, $22 \%-36 \%$ for SUI, and $5.5 \%-9 \%$ for UUI. ${ }^{1,35}$

Højberg et $\mathrm{al}^{9}$ have shown an increased prevalence of $\mathrm{UI}$ in adolescent population in pregnancy, but did not give much importance to the fact, saying that it could be caused by reporting bias because young women may be more aware of UI and have a lower threshold of reporting symptoms of UI.
However, Parden et $\mathrm{al}^{14}$ showed that adolescents presented less awareness of PFD, including UI.

In a study by Ege et al,${ }^{36}$ it was observed that younger ages were found to constitute risks in terms of UI. They justified that these results revealed a relationship between level of education and UI, also establishing that low-income individuals face increasing risk because as educational levels increase, so do income levels, and parallel to this, sensitivity toward maintaining good health and benefiting from available services is more developed. However, this study used a crude logistic regression model, not adjusting for sociodemographic confounding factors. In our study, UI was statistically more prevalent in adolescent population, by both crude and adjusted model analysis.

Moreover, UDI score was also higher in adolescent population, showing that in addition to urinary losses adolescents also presented other complaints such as difficulty in emptying the bladder and increased urinary frequency. ${ }^{24}$

In relation to FI, there was an increased prevalence of solid and/or liquid stool loss in adolescents' group (19.5\%) when compared with young women $(4.3 \%)$ with $\mathrm{PR}=4.4$, 95\% CI 1.36-14.27. As for UI, prevalence of FI in adolescents' group was higher than that found in previous studies in women in general at postpartum, of 3.3\%-6.3\%. ${ }^{1,34,36}$ Similarly, the study by Parden et a $1^{14}$ showed that female adolescents, who were not in the puerperal period, presented a 7.5-fold higher prevalence in the probability of FI symptoms when compared to young women.

POP did not present a statistically significant difference among age groups, but the only question that evidences the presence of POP in the PFDI-20 questionnaire is related to a symptom of POP stage 4 when it is already possible to visualize the descent of the organ below vaginal introitus; ${ }^{24}$ however, when analyzing POPDI score that evaluates symptoms related to the development of organ prolapse, we observed an increased score in the adolescent population, and therefore with symptoms that may be indicating the beginning of the development of this pathology that has so much impact on women's lives.

Analyzing the PFDI-20 questionnaire, it is observed that POPDI and total PFDI scores have high values both in the adolescents' group and in late adolescents' group, which shows that not only adolescents but also girls in transition from adolescence to adulthood report higher PFD symptoms.

In a case-control study conducted by Moalli et al in 2003 to identify risk factors associated with the development of PFD in women who undergo surgical correction, they identified that younger age ( $<25$ years) at first delivery was significantly associated with subsequent development of PFD. ${ }^{37}$ 
As PFD is always closely associated with the type of delivery, ${ }^{38,39}$ we performed an analysis to compare PFD between vaginal and cesarean deliveries according to age groups.

The influence of mode of delivery on occurrence of PFD is still uncertain, but studies in women in general show that cesarean section appears to protect against these symptoms, and vaginal delivery is highly associated with pelvic floor injury. ${ }^{19,20}$

Nevertheless, in our study, when PFD was compared between vaginal and cesarean deliveries, according to age groups results were remarkable. It was observed that among patients whose baby was born by vaginal delivery, no statistically significant differences were found between age groups, except for the occurrence of FI that was 9.3-fold increased in adolescents' group compared with young women's group.

As can be seen in Table 2, only two cases of instrumental delivery were observed, which occurred in adolescent girls. In this age group, vaginal delivery is more prevalent, ${ }^{40,41}$ and in our study greater complications were observed, with the need to use vacuum extractor during delivery. Adolescence is considered a potential risk factor due to physical and psychological immaturity, which can influence the labor. Insecurity and emotional instability can disrupt the evolution of labor; as a result, instrumental delivery could be necessary. ${ }^{42}$

Due to low prevalence of instrumental deliveries in the sample studied, a detailed analysis of this procedure was not possible.

However, when analyzing the influence of cesarean delivery among age groups, there is an increase in the prevalence of UI, UUI, FI, and POPDI, UDI and total PFDI scores among adolescents, which shows that this population has greater deleterious effects to the pelvic floor when their babies were born by cesarean sections.

We observed extremely high rates of cesarean sections (43.9\% in adolescents' group and 65.3\% in young women's group) within an unselected population, which is above the $10 \%-15 \%$ recommended by WHO. ${ }^{43}$

In Brazil, elective cesarean section without labor is a common procedure, sometimes justified by a maternal choice and protective factor for the development of PFD. ${ }^{44,45}$ In some cases, cesarean section is indicated due to obstetric intercurrences such as pregnancy-specific hypertensive disease, failure to progress, or cephalopelvic disproportion, among others. ${ }^{44,46}$

Our results showed that cesarean delivery has a negative influence on PFD symptoms among adolescents. According to Rortveit et al, the risk of UI is higher among women who have had cesarean sections than among nulliparous women. ${ }^{6}$
PFD are strongly associated with female gender, pregnancy, parity, and instrumental delivery. ${ }^{47}$

The results of our study reinforce the need for investment in public policies to reduce cesarean rates, especially in adolescents, and to implement issues about pelvic floor health education in primary care with activities involving adolescents and late adolescents population because PFD entails great social losses and impacts negatively on the quality of life of these girls. ${ }^{14,15,18}$

However, like any cross-sectional study, this study presents limitations due to the type of study, besides the lack of details in medical records, which makes it difficult to identify associated factors in retrospective studies. Epidemiologic studies with a longitudinal study design could be used to further characterize risk factors and etiology of PFD in the adolescent population.

In addition, the lack of statistical significance for differences in prevalence of the outcomes may be related to the sample size of the adolescent subgroup $(n=41)$. In contrast, this sample size may be related to the difficulty of recruiting girls in this age group, besides being a less frequent phenomenon. This means that the differences found actually exist, but the absence of differences, in particular in comparisons concerning the vaginal deliveries may be due to the adolescent group sample size. Besides, there are no data in Western Amazon for the sample size determination.

Moreover, the fact that the study was developed in a single city with possible regional genetic susceptibility can generate bias due to customs and conditions of childbirth inherent to the region studied.

This study provides unprecedented and important information regarding adolescent health, which is a population vulnerable to the occurrence of negative health outcomes in general. ${ }^{40,48,49}$ Seeking for treatment for PFD is neglected by the general population, who see the problems as inherent to the puerperal condition, and this becomes more complicated among the adolescent population as a result of shyness, insecurity, and fragility, making it harder to access the health system, and information and treatment may be late or, sometimes, even neglected in this population. ${ }^{50}$

The evaluation of PFD in adolescents is scarce, and our results point to the high prevalence of these symptoms. In fact, in developing countries with high adolescent pregnancy rates, primary care providers should consider addressing PFD symptoms in adolescence because of the multifactorial risk of development and evolution of the disease, ${ }^{51}$ as well as specific characteristics related to psychosocial and behavioral attitudes at this stage of woman's life. 


\section{Conclusion}

In conclusion, adolescents present higher prevalence and symptoms of PFD; furthermore, cesarean delivery has a greater negative influence on the pelvic floor of adolescents when compared with young women. This reinforces the importance of PFD investigation among the adolescent population, mainly in developing countries, which have high rates of adolescent pregnancy and cesarean section.

\section{Acknowledgments}

The authors wish to acknowledge Ociene Alves da Silva Ferro, Neli Santos Verçosa Neta, Thaianny Santos de Araújo, Pamera da Silva Pereira, Karoany Moreira Teles, Paula do Nascimento Guedes, Maria de Jesus Souza da Silva, Aline de Oliveira Costa, Marciela Cunha De Lima, Antônia Raline Lima da Silva and Milleny Maria Paiva Souza for assisting in the research's data collection. This study was supported by a grant between ABC Medical School (FMABC) and Acre State Government (Institutional Agreement number 007/2015).

\section{Author contributions}

All authors certify that they have participated sufficiently in the work to take public responsibility for the content, including participation in the concept, design, analysis, writing, or revision of the manuscript.

LTSZ, EFSS, FWSF, FA, IMPB, RDR, ICES, and LCA developed the study design and methodology. LTSZ, EFSS, IMPB, FA, ICES, and LCA were involved with data management. LTSZ, EFSS, FWSF, RDR, ICES, and LCA conducted the data analyses and drafted the manuscript. LTSZ, FWSF, FA, IMPB, RDR, ICES, and LCA were involved with editing the manuscript. All authors contributed toward data analysis, drafting and revising the paper and agree to be accountable for all aspects of the work.

\section{Disclosure}

The authors report no conflicts of interest in this work.

\section{References}

1. Ng K, Cheung RY, Lee LL, Chung TK, Chan SS. An observational follow-up study on pelvic floor disorders to 3-5 years after delivery. Int Urogynecol J. 2017;28(9):1393-1399.

2. Durnea CM, Khashan AS, Kenny LC, Tabirca SS, O'Reilly BA. The role of prepregnancy pelvic floor dysfunction in postnatal pelvic morbidity in primiparous women. Int Urogynecol J. 2014;25(10):1363-1374.

3. Diez-Itza I, Arrue M, Ibañez L, Murgiondo A, Paredes J, Sarasqueta C. Factors involved in stress urinary incontinence 1 year after first delivery. Int Urogynecol J. 2010;21(4):439-445.

4. Fritel X, Fauconnier A, Bader G, et al. Diagnosis and management of adult female stress urinary incontinence: guidelines for clinical practice from the French College of Gynaecologists and Obstetricians. Eur J Obstet Gynecol Reprod Biol. 2010;151(1):14-19.
5. Nygaard I, Barber MD, Burgio KL, et al. Prevalence of symptomatic pelvic floor disorders in US women. JAMA. 2008;300(11):1311-1316.

6. Maclennan AH, Taylor AW, Wilson DH, Wilson D. The prevalence of pelvic floor disorders and their relationship to gender, age, parity and mode of delivery. BJOG. 2000;107(12):1460-1470.

7. Kepenekci I, Keskinkilic B, Akinsu F, et al. Prevalence of pelvic floor disorders in the female population and the impact of age, mode of delivery, and parity. Dis Colon Rectum. 2011;54(1):85-94.

8. Pereira LC, Botelho S, Marques J, et al. Electromyographic pelvic floor activity: Is there impact during the female life cycle? Neurourol Urodyn. 2016;35(2):230-234.

9. Højberg KE, Salvig JD, Winsløw NA, Lose G, Secher NJ. Urinary incontinence: prevalence and risk factors at 16 weeks of gestation. Br J Obstet Gynaecol. 1999;106(8):842-850.

10. Hvidman L, Hvidman L, Foldspang A, Mommsen S, Bugge Nielsen J. Correlates of urinary incontinence in pregnancy. Int Urogynecol J Pelvic Floor Dysfunct. 2002;13(5):278-283.

11. Rortveit G, Hunskaar S. Urinary incontinence and age at the first and last delivery: the Norwegian HUNT/EPINCONT study. Am J Obstet Gynecol. 2006;195(2):433-438.

12. [No authors listed]. Young people's health-a challenge for society. Report of a WHO Study Group on young people and "Health for All by the Year 2000". World Health Organ Tech Rep Ser. 1986;731:1-117.

13. Association of Maternal and Child Health Programs. A Conceptual Framework for Adolescent Health: A Collaborative Project of the Association of Maternal and Child Health Programs and the National Network of State Adolescent Health Coordinators; 2005. Available from: http://www.amchp.org/programsandtopics/AdolescentHealth/ Documents/conc-framework.pdf. Accessed July 24, 2018.

14. Parden AM, Griffin RL, Hoover K, et al. Prevalence, awareness, and understanding of pelvic floor disorders in adolescent and young women. Female Pelvic Med Reconstr Surg. 2016;22(5):346-354.

15. Hebert-Beirne JM, O'Conor R, Ihm JD, Parlier MK, Lavender MD, Brubaker L. A pelvic health curriculum in school settings: the effect on adolescent females' knowledge. J Pediatr Adolesc Gynecol. 2017;30(2): 188-192.

16. Delatorre MZ, Patias ND, Dias ACG. Educational practices and the relationship between parents and their pregnant and non-pregnant adolescent daughters. Journal of Human Growth and Development. 2015; 25(2):141-150.

17. Brasil Ministério da Saúde. Informações de Saúde. Sistema de informações sobre nascidos vivos (SINASC) [Health Information. Information system on live births (SINASC)]. DATASUS; 2012. Available from: http://tabnet.datasus.gov.br/cgi/deftohtm.exe?sinasc/cnv/nvbr.def. Accessed July 24, 2018. Portuguese.

18. Svanemyr J, Amin A, Robles OJ, Greene ME. Creating an enabling environment for adolescent sexual and reproductive health: a framework and promising approaches. $J$ Adolesc Health. 2015;56(1 Suppl): S7-S14.

19. de Araujo CC, Coelho SA, Stahlschmidt P, Juliato CRT. Does vaginal delivery cause more damage to the pelvic floor than cesarean section as determined by 3D ultrasound evaluation? A systematic review. Int Urogynecol J. 2018;29(5):639-645.

20. Rørtveit G, Hannestad YS. Association between mode of delivery and pelvic floor dysfunction. Tidsskr Nor Legeforen. 2014;134(19): $1848-1852$.

21. von Elm E, Altman DG, Egger M, et al. The Strengthening the Reporting of Observational Studies in Epidemiology (STROBE) statement: guidelines for reporting observational studies. Lancet. 2007; 370(9596):1453-1457.

22. Romano M, Cacciatore A, Giordano R, La Rosa B. Postpartum period: three distinct but continuous phases. J Prenat Med [Internet]. 2010; 4(2):22-25.

23. Arouca MA, Duarte TB, Lott DA, et al. Validation and cultural translation for Brazilian Portuguese version of the Pelvic Floor Impact Questionnaire (PFIQ-7) and Pelvic Floor Distress Inventory (PFDI-20). Int Urogynecol J. 2016;27(7):1097-1106. 
24. Barber MD, Walters MD, Bump RC. Short forms of two condition-specific quality-of-life questionnaires for women with pelvic floor disorders (PFDI-20 and PFIQ-7). Am J Obstet Gynecol. 2005;193(1): 103-113.

25. Haylen BT, de Ridder D, Freeman RM, et al. An International Urogynecological Association (IUGA)/International Continence Society (ICS) joint report on the terminology for female pelvic floor dysfunction. Neurourol Urodyn. 2010;29(1):4-20.

26. Gafni-Kane A, Goldberg RP, Sand PK, Botros SM. Enhanced interpretability of the PFDI-20 with establishment of reference scores among women in the general population. Neurourol Urodyn. 2012;31(8): 1252-1257.

27. Valsky DV, Cohen SM, Lipschuetz M, et al. Third- or fourth-degree intrapartum anal sphincter tears are associated with levator ani avulsion in primiparas. J Ultrasound Med. 2016;35(4):709-715.

28. Rostaminia G, Peck JD, van Delft K, Thakar R, Sultan A, Shobeiri SA. New measures for predicting birth-related pelvic floor trauma. Female Pelvic Med Reconstr Surg. 2016;22(5):292-296.

29. Koc O, Duran B, Ozdemirc S, Bakar Y, Ozengin N. Is cesarean section a real panacea to prevent pelvic organ disorders? Int Urogynecol J. 2011;22(9):1135-1141.

30. Burgio KL, Borello-France D, Richter HE, et al. Risk factors for fecal and urinary incontinence after childbirth: the childbirth and pelvic symptoms study. Am J Gastroenterol. 2007;102(9):1998-2004.

31. Alperin M, Cook M, Tuttle LJ, Esparza MC, Lieber RL. Impact of vaginal parity and aging on the architectural design of pelvic floor muscles. Am J Obstet Gynecol. 2016;215(3):312.e1-313.e9.

32. Swift S, Woodman P, O’Boyle A, O’Boyle A, et al. Pelvic Organ Support Study (POSST): the distribution, clinical definition, and epidemiologic condition of pelvic organ support defects. Am J Obstet Gynecol. 2005;192(3):795-806.

33. Stewart CP, Katz J, Khatry SK, et al. Preterm delivery but not intrauterine growth retardation is associated with young maternal age among primiparae in rural Nepal. Matern Child Nutr. 2007;3(3):174-185.

34. Kongnyuy EJ, Nana PN, Fomulu N, Wiysonge SC, Kouam L, Doh AS. Adverse perinatal outcomes of adolescent pregnancies in Cameroon. Matern Child Health J. 2008;12(2):149-154.

35. Chan SS, Cheung RY, Yiu KW, Lee LL, Chung TK. Prevalence of urinary and fecal incontinence in Chinese women during and after their first pregnancy. Int Urogynecol J. 2013;24(9):1473-1479.

36. Ege E, Akın B, Altuntuğ K, Benli S, Ariöz A. Prevalence of urinary incontinence in the 12-month postpartum period and related risk factors in Turkey. Urol Int. 2008;80(4):355-361.

37. Moalli PA, Jones Ivy S, Meyn LA, Zyczynski HM. Risk factors associated with pelvic floor disorders in women undergoing surgical repair. Obstet Gynecol. 2003;101(5 Pt 1):869-874
38. Adaji SE, Olajide FM. Pelvic floor distress symptoms within 9 weeks of childbirth among Nigerian women. Eur J Obstet Gynecol Reprod Biol. 2014;174(1):54-58.

39. Rogers RG, Leeman LM, Borders N, et al. Contribution of the second stage of labour to pelvic floor dysfunction: a prospective cohort comparison of nulliparous women. BJOG. 2014;121(9):1145-1154.

40. Kawakita T, Wilson K, Grantz KL, Landy HJ, Huang CC, Gomez-Lobo V. Adverse maternal and neonatal outcomes in adolescent pregnancy. J Pediatr Adolesc Gynecol. 2016;29(2):130-136.

41. Muganyizi PS, Kidanto HL. Impact of change in maternal age composition on the incidence of Caesarean section and low birth weight: analysis of delivery records at a tertiary hospital in Tanzania, 1999-2005. BMC Pregnancy Childbirth. 2009;9(1):1-7.

42. World Health Organization. Adolescent Pregnancy - Issues in Adolescent Health and Development; 2004. Available from: http:// apps.who.int/iris/bitstream/handle/10665/42903/9241591455_eng. pdf? sequence=1. Accessed July 24, 2018.

43. WHO Statement on Caesarean Section Rates. Geneva: World Health Organization; 2015 (WHO/RHR/15.02).

44. Gama SGN, Viellas EF, Schilithz AOC, et al. Factors associated with caesarean section among primiparous adolescents in Brazil, 2011-2012. Cad. Saúde Pública. 2014;30(1):S117-S127.

45. Diniz CS, Miranda MJ, Reis-Queiroz J, Queiroz MR, Salgado HO. Why do women in the private sector have shorter pregnancies in Brazil? Left shift of gestational age, caesarean section and inversion of the expected disparity. J Hum Growth Dev. 2016;26(1):33-40.

46. Groen RS, Trelles M, Caluwaerts S, et al. A cross-sectional study of indications for cesarean deliveries in Médecins Sans Frontières facilities across 17 countries. Int J Gynaecol Obstet. 2015;129(3):231-235.

47. Rortveit G, Daltveit AK, Hannestad YS, Hunskaar S, Norwegian EPINCONT Study. Urinary incontinence after vaginal delivery or cesarean section. N Engl J Med. 2003;348(10):900-907.

48. Torvie AJ, Callegari LS, Schiff MA, Debiec KE. Labor and delivery outcomes among young adolescents. Am JObstet Gynecol. 2015;213(1): 95.e1-95.e8.

49. Abreu LC, Pereira VX, Silva RP, Junior HM, Bezerra IM. The right to scientific information: one of the main elements of the unified health system. J Hum Growth Dev. 2017;27(3):258-261.

50. Buurman MB, Lagro-Janssen AL. Women's perception of postpartum pelvic floor dysfunction and their help-seeking behaviour: a qualitative interview study. Scand J Caring Sci. 2013;27(2):406-413.

51. Bezerra IM, Sorpreso IC. Concepts and movements in health promotion to guide educational practices. J Hum Growth Dev. 2016;26(1):11-20.
International Journal of Women's Health

\section{Publish your work in this journal}

The International Journal of Women's Health is an international, peerreviewed open-access journal publishing original research, reports, editorials, reviews and commentaries on all aspects of women's healthcare including gynecology, obstetrics, and breast cancer. The manuscript management system is completely online and includes

\section{Dovepress}

a very quick and fair peer-review system, which is all easy to use Visit http://www.dovepress.com/testimonials.php to read real quotes from published authors. 